\title{
Commentary
}

\section{Food environment research is needed to improve nutrition and well-being in Asia and the Pacific}

\author{
Penny Farrell', Cut Novianti Rachmi ${ }^{2}$, Georgina Mulcahy' ${ }^{1}$ Matthias Helble ${ }^{3}$ \\ and Anne Marie Thow ${ }^{1, *}$ \\ 'Menzies Centre for Health Policy and Economics, School of Public Health, University of Sydney, Sydney, NSW 2006, \\ Australia: ${ }^{2}$ Reconstra Utama Integra, Kota Jakarta Selatan, Daerah Khusus Ibukota Jakarta, Indonesia: ${ }^{3}$ Regional \\ Cooperation and Integration Division, Economic Research and Regional Cooperation Department, Asian Development \\ Bank, Manila, Philippines
}

Submitted 11 February 2021: Final revision received 7 May 2021: Accepted 25 May 2021: First published online 28 May 2021

Developing countries in Asia and the Pacific have experienced significant economic growth over the past five decades. In low- and middle-income countries in Asia for instance, per capita GDP increased nearly fivefold ${ }^{(1)}$ which has led to a reduction in extreme poverty (living on $<\$ 1.90$ per day) from $54 \%$ in 1990 to $7 \%$ in $2015^{(2)}$. Yet, these economic gains have not translated into similar advances in nutrition and health outcomes for the diverse countries across the region. Countries in the region are now experiencing a triple burden of malnutrition, with co-existing undernutrition (stunting, underweight and wasting), dietrelated chronic diseases (linked to overweight and obesity) and micronutrient deficiencies (especially iron-deficiency anaemia $)^{(3)}$. Despite decline in the prevalence of undernutrition over recent decades, almost half a billion people in Asia and the Pacific remain undernourished, and stunting rates amongst children under five exceed $20 \%$ in most countries $^{(4)}$. Over the past 40 years, a complex interplay of drivers has led to a rapid rise in the rates of obesity and diet-related chronic diseases - notably in the Pacific region $^{(3,5)}$. These multiple forms of malnutrition do not just exist at the national level, but have also been observed at the household level (e.g. an underweight child and an overweight mother within the same household) in Indonesia, Malaysia, the Philippines and Vietnam ${ }^{(6)}$.

This triple burden of malnutrition is undermining the gains from economic growth in the region - both in terms of the social and personal costs of malnutrition and the economic cost for the region. Overweight and obesity alone constitute an estimated $12 \%$ of total health care expenditures in the region ${ }^{(7)}$. In addition, poor early childhood nutrition has significant productivity costs through its impact on human capital (the aggregate levels of education, training, skills and health in a population) ${ }^{(8)}$.

Early estimates suggest that the economic and food system impacts of COVID-19 are likely to worsen these indicators across the region ${ }^{(9)}$. Thus, it is a critical time to consider the role of research in addressing malnutrition effectively across the region. In this commentary, we examine the limited literature that exists on food environments in Asia and the Pacific and reflect on the opportunities to strengthen research and policy to improve outcomes for nutrition.

\section{Policy for the triple burden of malnutrition in the region}

The causes of malnutrition are complex, but there is increasing recognition that the decisions people make about their food consumption are influenced by external factors in their food environments, such as physical availability of food, food prices, marketing and retail ${ }^{(10,11)}$. As dietary change escalates in Asia and the Pacific region, a comprehensive response will also need to include consideration of the food environment - not only as a driver of change but also as an important focus for solutions ${ }^{(4)}$. There is a significant opportunity for healthier food environments to support healthier diets and contribute to addressing all forms of malnutrition across the population.

There is a high level of political commitment to address the triple burden of malnutrition across Asia and the Pacific ${ }^{(12,13)}$. Countries in the region, particularly across Asia, have made notable progress in addressing the 
historically high burden of undernutrition, mainly through nutrition-specific (individual, community focussed) interventions targeting the immediate determinants of nutrition $^{(14-16)}$. However, with the changing burden of malnutrition threatening health and economic gains, there is a need to complement such approaches with food environment interventions to support availability, convenience, attractiveness and affordability of healthy foods ${ }^{(17)}$. The WHO and United Nations Food and Agriculture Organization recommend a comprehensive package of interventions to promote healthy diets and prevent noncommunicable diseases, including school food policies, interpretive labelling, fiscal policy measures (including taxation) and restrictions on marketing of unhealthy foods and beverages to children ${ }^{(17,18)}$. Within the region, there are examples of comprehensive school food policies in Malaysia and South Korea, mandatory interpretive nutrition labelling in Thailand and Sri Lanka, taxes on sugar sweetened beverages in at least sixteen countries and territories and strong restrictions on marketing to children under 12 in Taiwan $^{(4)}$.

Despite these efforts, malnutrition in Asia and the Pacific remains a significant challenge, and it is clear that success will require strengthening policies to promote healthy food environments. Developing effective policies, however, will require improved knowledge of the nature of food environments in the region. Such evidence will support governments in the region to tackle the problem of malnutrition and support civil society to convincingly advocate for policy change.

\section{Changing food environments in Asia Pacific region}

Food availability has changed markedly in the region, particularly as a result of urbanisation. Asia leads the world in its rapid urbanisation, with over a quarter of the world's estimated urban population growth by 2050 expected to occur in India and China ${ }^{(19)}$. In terms of nutrition, urban, as opposed to rural food environments, tend to offer greater food diversity. However, this has also been accompanied by rising availability of processed or pre-prepared foods high in fat, salt and sugar ${ }^{(19-23)}$. A critical upstream driver of availability is trade in food and beverages. Rising international food trade has increased the availability of diverse foods and contributed to improvements in dietary quality and reductions in undernutrition ${ }^{(24)}$. However, this very much depends on the commodity being traded, and limited research indicates that imports of cheap, energy-dense foods and sugar-sweetened beverages are a concern across the region ${ }^{(25,26)}$. For instance, India and China are two of the top five markets worldwide for sales of sugary drinks ${ }^{(27)}$.

Food price also has a significant influence on food consumption habits in Asia and the Pacific ${ }^{(19,28,29)}$. A major challenge is that the cost of nutritious food, such as fruit and vegetables, is often higher than less healthy foods high in sugar, salt and fat ${ }^{(30,31)}$. Our recent analysis of food trade data across the region indicates that the price of less healthy food (including fatty meat and snack foods) has risen at a slower rate than for healthier foods (including fresh fruit and vegetables, root crops and whole grain cereal) ${ }^{(4)}$. As a result, the price gap between less healthy foods and healthier foods has widened across the region from 2003 to 2018, with less healthy foods becoming relatively cheaper. Limited availability of affordable nutritious foods is a particular barrier to healthy diets among the urban poor; $69 \%$ of the world's total urban poor live in Asia( ${ }^{32)}$. Extremely poor urban households can spend more than half of their household budgets on food and often have low diet quality ${ }^{(22,33)}$. These trends are concerning from a health equity perspective, particularly for poor urban populations who are often more dependent than rural populations on purchased foods ${ }^{(19)}$. History has shown that recent economic crises, notably the 2007-2008 global financial crisis and the 1997-1998 Asian financial crisis, have had significant impacts on food and nutrition security as incomes, food prices and poverty reduction and nutrition programmes were impacted ${ }^{(3,34)}$. There is little doubt that the economic downturn associated with the COVID-19 pandemic will influence food and nutrition security ${ }^{(35)}$.

The nature and prevalence of food marketing in the region is relatively poorly documented, despite the fact that it can have a major influence on consumption patterns ${ }^{(36)}$. Two recent studies suggest that food advertising is dominated by foods associated with the nutrition transition, such as snack foods and sugary beverages ${ }^{(37,38)}$. In addition, marketing targeting children is an evident concern in the region. Studies in Thailand, China, Indonesia, Malaysia and South Korea have found that the most frequently advertised (food) product was sugar-sweetened drinks, and that rates of non-core (less healthy) food advertising were highest during viewing times most popular with children ${ }^{(39,40)}$. It is also clear that increasingly intentional strategies are being used to market unhealthy foods and beverages to children, including promotional characters, free gifts, health claims and sponsorship of school $\operatorname{sport}^{(37,40-45)}$.

Access to healthy food is also heavily influenced by the nature of food retail, which has changed markedly across the region and remains extremely diverse - including supermarkets, open market vendors, informal street vendors and restaurants ${ }^{(19,22,23)}$. Wet markets selling fresh food remain a vital component of food retail and can be associated with increased vegetable consumption ${ }^{(20,46)}$. However, the urban poor often need to travel long distances, incurring additional expenses, to overcrowded retail markets or street stalls where hygiene, drainage, clean water and waste disposal are often insufficient ${ }^{(47)}$. In contrast, consumers with middle or high incomes often shop at 
modern supermarkets, which tend to be conveniently located and offer a diverse range of foods at lower prices $^{(47)}$. The growth of the grocery retail sector, or 'supermarketization', is a key driver of ongoing food system change in low- and middle-income countries in the region $^{(48)}$. They have both positive and negative implications for access to healthy food: on the one hand, they offer a diverse range of nutritious foods with (often) high food safety standards; on the other, they can increase access to highly processed, less healthy foods ${ }^{(49,50)}$. There is also evidence to suggest that the retail food environment surrounding schools in the region preference less healthy options, such as soft drinks and fast food outlets ${ }^{(42,51)}$.

With rising use of the internet and mobile technologies in the past ten years, food delivery services using an online application have grown rapidly in Asia, further accelerating during the COVID-19 pandemic ${ }^{(52)}$. Food delivery services have been one of the solutions to obtain food during the COVID-19 pandemic; however, the nutritional value of these takeaway foods is often low; they are often high in salt and fat and energy dense ${ }^{(53)}$.

\section{Opportunities for future research}

Although countries in the Asia Pacific region have a high level of political will to address the significant burden of malnutrition in all its forms, the implementation of context-specific food environment policies is hampered by limited data on food prices, availability, marketing and retail. Improved research into food environments in the region would support policy makers to better target these policies and also support monitoring of policy implementation and impacts. While there are clear indications that food environment change is contributing to the dietary transition in the region, research to date has been patchy.

Informing strong policies to improve food environments will require further in-depth research at the regional, national and local levels with a particular focus on subnational trends and contextual differences, as well as on vulnerable populations. Priorities for research include improving understanding of relative food availability for example by mapping of food retail outlets, particularly in low-income neighbourhoods and surrounding schools, systematic analysis of pricing trends at national and cross-national levels, and monitoring of marketing practices. It will also be beneficial to examine food environments in light of the traditional healthy food cultures in the region. In South Korea and French Polynesia, integrated food policy that intentionally fosters traditional food cultures has supported positive dietary change ${ }^{(54,55)}$.

In conclusion, more granular and context-specific data regarding the food environments in which people make decisions regarding their food purchasing and consumption will be invaluable in informing targeted and welldesigned policy interventions in Asia and the Pacific region. It will also be essential for monitoring the effectiveness of policy interventions to improve diets and health.

\section{Acknowledgements}

Acknowledgements: P.F. and A.M.T. would also like to acknowledge support from ACIAR project FIS/2018/155. Financial support: This commentary draws upon research conducted for the Asian Development Bank - ADOU 2020 Theme Chapter: Wellness for Happiness (Nutrition in Developing Asia) (52216-003). Conflict of interest: There are no conflicts of interest. Authorship: The article was conceptualised by P.F., A.M.T., C.N.R., M.H. P.F, A.M.T., C.N.R. and G.M. contributed to literature review and analysis. Original draft was written by P.F. All authors contributed to writing and editing the final draft. Ethics of human subject participation: Not applicable.

\section{References}

1. Asian Development Bank (2020) Asia's Journey to Prosperity: Policy, Markets and Technology Over 50 Years. Manila: Asian Development Bank.

2. Asian Development Bank (2020) Key Indicators for Asia and the Pacific 2020. Manila: Asian Development Bank.

3. FAO, UNICEF, WFP et al. (2019) Placing Nutrition at the Centre of Social Protection. Asia and the Pacific Regional Overview of Food Security and Nutrition 2019. Bangkok: FAO.

4. Thow AM, Farrell P, Helble M et al. (2020) Eating in Developing Asia: Trends, Consequences and Policies. Background Paper for the Asian Development Outlook 2020 Update: Wellness in Worrying Times. Manila: Asian Development Bank.

5. Murray CJ, Aravkin AY, Zheng P et al. (2020) Global burden of 87 risk factors in 204 countries and territories, 1990-2019: a systematic analysis for the Global Burden of Disease Study 2019. Lancet 396, 1223-1249.

6. Rachmi CN, Li M \& Baur LA (2018) The double burden of malnutrition in Association of South East Asian Nations (ASEAN) countries: a comprehensive review of the literature. Asia Pac J Clin Nutr 27, 736.

7. Helble M \& Francisco K (2018) Chapter 8: The imminent obesity crisis in Asia and the Pacific: first cost estimates. In Wealthy but Unhealthy: Overweight and Obesity in Asia and the Pacific: Trends, Costs, and Policies for Better Health, pp. 170-192. Tokyo: Asian Development Bank Institute (ADBI).

8. Lim SS, Updike RL, Kaldjian AS et al. (2018) Measuring human capital: a systematic analysis of 195 countries and territories, 1990-2016. Lancet 392, 1217-1234.

9. Asian Development Bank (2020) Food Security in Asia and the Pacific Amid the COVID-19 Pandemic. Manila: Asian Development Bank.

10. Turner C, Kalamatianou S, Drewnowski A et al. (2020) Food environment research in low- and middle-income countries: a systematic scoping review. Adv Nutr 11, 387-397.

11. Turner C, Aggarwal A, Walls H et al. (2018) Concepts and critical perspectives for food environment research: a global framework with implications for action in low-and middleincome countries. Global Food Secur 18, 93-101. 
12. Dodd R, Reeve E, Sparks E et al. (2020) The politics of food in the Pacific: coherence and tension in regional policies on nutrition, the food environment and non-communicable diseases. Public Health Nutr 23, 168-180.

13. ASEAN (2017) ASEAN Leaders' Declaration on Ending All Forms of Malnutrition. Association of South East Asian Nations. https://asean.org/wp-content/uploads/ 2017/11/2.-ADOPTION_2017_ALD-on-Ending-All-Formsof-Malnutrition_Endorsed-by-the-AHMM.pdf （accessed March 2020).

14. Thow AM, Kadiyala S, Khandelwal S et al. (2016) Toward food policy for the dual burden of malnutrition: an exploratory policy space analysis in India. Food Nutr Bull 37, 261-274.

15. Headey D \& Palloni G (2019) Water, sanitation, and child health: evidence from subnational panel data in 59 countries. Demography 56, 729-752.

16. Headey DD \& Hoddinott J (2015) Understanding the rapid reduction of undernutrition in Nepal, 2001-2011. PLoS One 10, e0145738.

17. FAO \& WHO (2014) Second International Conference on Nutrition. Conference Outcome Document: Rome Declaration on Nutrition. ICN2 2014/2. Rome: Food and Agriculture Organization of the United Nations and World Health Organization.

18. World Health Organization (2020) Regional Action Framework on Protecting Children from the Harmful Impact of Food Marketing in the Western Pacific. Manila: WHO Regional Office for the Western Pacific.

19. FAO (2018) Asia and the Pacific Regional Overview of Food Security and Nutrition 2018 - Accelerating Progress Towards the SDGs. Bangkok: FAO.

20. Hawkes C, Harris J \& Gillespie S (2017) Chapter 4: Urbanization and the nutrition transition. In IFPRI Global Food Policy Report. Washington, DC: International Food Policy Research Institute (IFPRI). https://doi.org/10.2499/ 9780896292529_04.

21. Graziano da Silva J \& Máximo T (2019) It is time to improve nutrition and fast-track food security for all, vol. 2019. SGD2 Advocacy Hub. https://sdg2advocacyhub.org/index.php/ chefs-manifesto/news/it-time-improve-nutrition-and-fasttrack-food-security-all (accessed January 2021).

22. Ruel MT, Garrett JL \& Yosef S (2017) Chapter 3: Food security and nutrition: growing cities, new challenges. In 2017 Global Food Policy Report. Washington DC: International Food Policy Research Institute (IFPRI). https://doi.org/10.2499/ 9780896292529_03.

23. Liu H, Wahl TI, Seale JL et al. (2015) Household composition, income, and food-away-from-home expenditure in urban China. Food Policy 51, 97-103.

24. García-Dorado SC, Cornselsen L, Smith R et al. (2019) Economic globalization, nutrition and health: a review of quantitative evidence. Globalization Health 15, 15.

25. Krivonos E \& Kuhn L (2019) Trade and dietary diversity in Eastern Europe and Central Asia. Food Policy 88, 101767.

26. Baker P, Kay A \& Walls H (2014) Trade and investment liberalization and Asia's noncommunicable disease epidemic: a synthesis of data and existing literature. Globalization Health 10, 66.

27. Popkin BM, Corvalan C \& Grummer-Strawn LM (2019) Dynamics of the double burden of malnutrition and the changing nutrition reality. Lancet 395, 65-74

28. Asian Development Bank (2011) Global Food Price Inflation and Developing Asia. Mandaluyong City, Philippines: Asian Development Bank.

29. Farrell P, Thow AM, Schuster S et al. (2019) Access to a nutritious diet in Samoa: local insights. Ecol Food Nutr $\mathbf{5 8}$, 189-206.
30. Headey DD \& Alderman HH (2019) The relative caloric prices of healthy and unhealthy foods differ systematically across income levels and continents. J Nutr 149, 2020-2033.

31. Dizon F \& Herforth A (2018) The Cost of Nutritious Food in South Asia. Washington DC: The World Bank.

32. Mathur OP (2013) Urban Poverty in Asia. Metro Manila: Asian Development Bank.

33. Oli N, Vaidya A \& Thapa G (2013) Behavioural risk factors of noncommunicable diseases among Nepalese urban poor: a descriptive study from a slum area of Kathmandu. Epidemiol Res Int 2013, 1-13.

34. Wiggins S \& Keats S (2015) Food Prices: 2014/15 Annual Review. London, UK: Overseas Development Institute.

35. Farrell P, Thow AM, Wate JT et al. (2020) COVID-19 and Pacific food system resilience: opportunities to build a robust response. Food Secur 12, 783-791.

36. Boyland EJ \& Whalen R (2015) Food advertising to children and its effects on diet: review of recent prevalence and impact data. Pediatr Diabetes 16, 331-337.

37. Liu P, Yu Y, King L et al. (2017) Snack and beverage consumption and preferences in a sample of Chinese children are they influenced by advertising? Asia Pac J Clin Nutr 26, $1125-1132$.

38. Chen SJ, Wu M, Wen LM et al. (2019) Status and trend of children's exposure to food advertising on free-to-air television in Shanghai. Fudan Univ J Med Sci 46, 378-382.

39. Kelly B, Hebden L, King L et al. (2016) Children's exposure to food advertising on free-to-air television: an Asia-Pacific perspective. Health Promot Int 31, 144-152.

40. Jaichuen N, Vandevijvere S, Kelly B et al. (2018) Unhealthy food and non-alcoholic beverage advertising on children's, youth and family free-to-air and digital television programmes in Thailand. BMC Public Health 18, 1-9.

41. Ng SH, Kelly B, Se CH et al. (2015) Obesogenic television food advertising to children in Malaysia: Sociocultural variations. Global Health Action 7, 25169.

42. Li M, Dibley MJ \& Yan H (2011) School environment factors were associated with BMI among adolescents in Xi'an City, China. BMC Public Health 11, 792.

43. Prathapan S, Wijewardena K \& Low WY (2016) Content analysis of food and beverages advertisements targeting children and adults on television in Sri Lanka. Asia-Pac J Public Health 28, 86S-92S.

44. Reeve E, Thow AM, Bell C et al. (2018) Implementation lessons for school food policies and marketing restrictions in the Philippines: a qualitative policy analysis. Globalization Health 14, 1-4.

45. Kelly B, King L, Jamiyan B et al. (2015) Density of outdoor food and beverage advertising around schools in Ulaanbaatar (Mongolia) and Manila (The Philippines) and implications for policy. Crit Public Health 25, 280-290.

46. Kelly M, Seubsman S-A, Banwell C et al. (2014) Thailand's food retail transition: supermarket and fresh market effects on diet quality and health. Br Food J 116, 1180-1193.

47. Seidler E (2000) Key Paper 2 - Feeding Asian cities: urban food distribution issues. Feeding Asian Cities, pp. 47-54. Bangkok: FAO.

48. Reardon T, Timmer CP \& Minten B (2012) Supermarket revolution in Asia and emerging development strategies to include small farmers. Proc Natl Acad Sci 109, 12332-12337.

49. Hawkes C (2008) Dietary implications of supermarket development: a global perspective. Dev Policy Rev 26, 657-692.

50. Baker P \& Friel S (2016) Food systems transformations, ultraprocessed food markets and the nutrition transition in Asia. Globalization Health 12, 80 .

51. Reeve E, Thow AM, Bell C et al. (2021) Identifying opportunities to strengthen school food environments in the Pacific: a case study in Samoa. BMC Public Health 21, 1-2. 
52. Voon V (2021) Food delivery in South East Asia almost tripled in 2020, accelerated by COVID-19. Momentum. https://thelowdown.momentum.asia/food-delivery-in-southeast-asia-almost-tripled-in-2020-accelerated-by-covid-19/ (accessed May 2021).

53. Ren J, Luo X, Zhao X et al. (2020) Takeaway food in Chengdu, Sichuan province, China: composition and nutritional value. Asia Pac J Clin Nutr 29, 883-898.
54. Engelberger L \& Johnson E (2013) Traditional foods of the Pacific: Go Local, a case study in Pohnpei, Federated States of Micronesia. In Diversifying Food and Diets: Using Agricultural Biodiversity to Improve Nutrition and Health, pp. 231-241 [J Fanzo, D Hunter, T Borelli et al., editors]. UK: Routledge.

55. Kim S, Moon S \& Popkin BM (2000) The nutrition transition in South Korea. Am J Clin Nutr 71, 44-53. 